\title{
OS SÓSIAS PARÓDICOS DE LOBO ANTUNES
}

\author{
Helenice Maria Reis Rocha \\ Universidade Federal de Minas Gerais
}

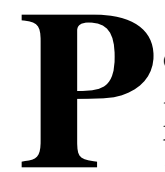

ercorri, neste estudo os caminhos da desconstrução paródica em Lobo Antunes na obra As Naus tomando por

base as reflexões de Linda Hutcheon e Mikail Bakthin sobre a paródia. Por tratar-se de um Livro que parodia todo o triunfalismo português sobre as grandes navegações e que desconstrói, através dos seus personagens, todo o mito do heró́smo que cercou este aspecto da história de Portugal, é que se usa o termo desconstrução paródica. Desconstrução porque desmonta idéias pré-estabelecidas e tradicionais na cultura portuguesa. Paródica, porque busca nos seus métodos os procedimentos da paródia. No caso de Lobo Antunes trata-se de uma paródia da história uma vez que ele submete os seus heróis a um travestimento histriônico que joga por terra toda a sua pompa e circunstância misturando-os à banalidade e ao non-sense da existência comum e do mundo contemporâneo, chegando à uma reflexão melancólica sobre a condição humana e sobre os tempos presentes. Neste sentido, Portugal se me afigura como um cadinho do mundo exposto a todas as vicissitudes da dor humana de viver diante da queda, da falência dos modelos antigos e do fracasso das utopias. O homem português deste século parece ser alguém desencantado e perseguido pelos próprios fantasmas e sem um lugar de inscrição nem no passado, nem no presente. Assim sendo Lobo Antunes funciona como todo artista deveria funcionar. Desmascara o discurso oficial e a sua tirania através da paródia, desconstrói o espaço da nossa estabilidade ingênua e joga lama nas nossas ilusões. 
Vejamos agora, em tese, como acontece o procedimento parodístico em Lobo Antunes. Normalmente, a paródia funciona como um deslocamento intencional de um modelo original tido como exemplar e pode ser viabilizada de uma forma histriônica, pela ridicularização, como ocorre em Rabelais, ou pode funcionar como uma reflexão crítica sobre textos tradicionais, sobre idéias emblemáticas na configuração da história, como por exemplo em Oswald de Andrade. Pode portanto levar ao riso ou à reflexão. Ou às duas coisas.

Em Lobo Antunes a experiência pode ser chapliniana. O que leva ao riso pode levar também ao choro, o que para alguns teóricos é a essência do humor. Diferentemente da experiência cômica que leva somente ao riso, a paródia em Lobo Antunes conduz personagens altamente louvados na história de Portugal ao patético e ao ridículo, numa atitude que Mikail Baktlin, no seu estudo sobre Rabelais chamaria de destronamento dos reis, destronamento do poder oficial.

Na confrontação, por exemplo, entre o imaginário que cercou as grandes navegações, a fantasia cede lugar à uma realidade que não tem nada de grandiosa e que é, no mais das vezes, cruel e devoradora como no caso da comparação das tágides camonianas com a decadência das mulheres das beiras do cais. Cumpre especificar os personagens em questão na narrativa. Figuram neste espaço os grandes navegadores, tais como, Pedro Álvares Cabral, Vasco da Gama entre outros. Camões também comparece, devidamente desvestido da sua dignidade de grande épico da Literatura Portuguesa. Um personagem importantíssimo, Manoel de Sousa Sepúlveda, vítima de um grande naufrágio à época das navegações, também aí aparece, devidamente parodiado. Também nos é apresentado o grande evangelizador, Francisco Xavier, devidamente desauratizado e jogado no grande círculo de prostituição e decadência do mundo, numa reflexão moral e nem um pouco engraçada sobre religião e comércio; reflexão esta que me parece subjacente, a toda a construção do texto. 
Explicitados alguns dos personagens, tentarei demonstrar o que Bakthin chamou de "sósias paródicos" em seu estudo sobre Rabelais dentro do contexto da obra de Lobo Antunes. A obra em questão é, sem dúvida, uma ironia com relação à uma ficção ingênua que se remete a si mesma, uma vez que esta narrativa nos joga na história, reescreve o discurso oficial de forma anarquista e no final nos faz engolir o riso porque, ao que parece, a intenção de desvestir a máscara da história é séria. Neste sentido, o que em Rabelais é alargamento dos espartilhos, é riso popular, em Lobo Antunes e denúncia de decadência.

Os personagens não aparecem ridicularizados, por exemplo, para levar ao riso pura e simplesmente e o desmascaramento do discurso oficial não é apenas uma conseqüência fortuita, mas antes um objetivo seriamente perseguido e conseguido nos mínimos detalhes.

Mas já que falamos em desconstrução, vamos também analisar alguns aspectos da construção de todo o triunfalismo épico que perpassa pelo menos um texto teórico da maior importância na história da Literatura Portuguesa. Através de Camões se percebe a idéia da predestinação a um grande destino, escrito pelos deuses do Olimpo, destino esse contrariado apenas por Baco. Vejamos o que nos diz a esse respeito Antônio José Saraiva, em suas reflexões sobre a épica camoniana:

Toda a complicada tecitura d'os Lusíadas tem um nó ou um ponto culminante: as núpcias do Gama e dos Barões com Tétis e as suas ninfas. Neste único ponto, em que o plano histórico e o plano mitológico se encontram, se desmascara toda a alegoria ou ficção estilística que o autor vinha tecendo desde o concílio dos Deuses. Por estas núpcias, entrando na imortalidade, os navegantes passam a ser da mesma carne que os heróis da mitologia, Homero e Virgílio. ${ }^{1}$

${ }^{1}$ SARAIVA, 1950, p.143. 
Percebe-se que o discurso épico compara os feitos dos portugueses aos feitos dos deuses do Olimpo, com os quais podiam medir forças de igual para igual, e, sobretudo triunfar, inclusive com a ajuda e cumplicidade das forças do amor, uma vez que tinham como principal defensora, Vênus, que proveio até às necessidades eróticas dos heróis navegantes com a arregimentação das ninfas de Tétis e a criação da Ilha dos Amores. Em suma, o destino dos portugueses já vem traçado nas estrelas e é grandioso. Vejamos no próprio texto camoniano alguns aspectos dessa construção.

Cessem do sábio grego do troiano

As navegações grandes que fizeram:

Cale-se de Alexandre e de Trajano

A fama das vitórias que tiveram;

Que eu canto o peito ilustre Lusitano,

A quem Netuno e Marte obedeceram.

Cesse tudo o que a Musa antiga canta,

Que outro valor mais alto se alevanta. ${ }^{2}$

Esta estrofe representa bem a grandiloqüência que perpassa todo o imaginário popular que cerca as grandes navegações portuguesas.

Enfim, quando os deuses do Olimpo se reúnem para decidir o destino da humana gente, o valor Lusitano se entremostra. Vejamos:

Eternos moradores do luzente,

Estelífero polo e claro assento.

Se do grande valor da forte gente

De Luso não perdeis o pensamento,

Deveis de ter sabido claramente

como é dos fados grandes certo intento,

Que por ela s'esqueçam os humanos

De assírios, persas, gregos e romanos. ${ }^{3}$

${ }^{2}$ CAMÕES, 1990, p.30.

${ }^{3}$ CAMÕES, 1990, p.37. 
O concílio dos deuses, com exceção de Baco, o Tebano, já esboça para os portugueses uma glória que, dentro do espírito da épica camoniana, levará ao esquecimento todos os grandes feitos da humanidade. E para engrandecer a glória portuguesa, nada melhor do que perigos muito sérios e atrozes, nada melhor do que guerras e confrontações perigosas e sobretudo um mar muitas vezes tenebroso e difícil como prevê o gigante Adamastor. Assim, os favores Tétis na Ilha dos Amores ganham o valor de um triunfo absoluto e a adversidade tem como prêmio a imortalidade. Quando Tétis mostra o Atlas para Vasco da Gama e faz previsões históricas, não está nada mais do que conferindo aos portugueses o domínio através do conhecimento e o poder através do método.

Mas convém não esquecer as palavras do velho do Restelo que de alguma forma entram em consonância com toda a desconstrução da épica portuguesa que se observa em Lobo Antunes. Vejamos:

Oh! Maldito o primeiro que, no mundo

Nas ondas velas pôs em seco lenho!

Dino da eterna pena do profundo, Se é justa a lei que sigo e tenho!

Nunca juízo algum alto e profundo

Nem cítara sonora ou vivo engenho,

Te dê por isso fama nem memória

Mas contigo se acabe o nome e glória. ${ }^{4}$

Parafraseando o velho do Restelo, Lobo Antunes se me afigura como uma parcela desta maldição. Para começar a analisá-lo descreverei em termos gerais o percurso narrativo no sentido de dar a perceber o lugar e o sentido dos personagens na obra.

Trata-se de um retorno. A saber, do retorno de Pedro Álvares Cabral vindo da África. Duplo retorno. Vem da África, como retornado da guerra civil, e do tempo, saído diretamente dos portais da história. Logo na alfândega ele é tratado como um qualquer

${ }^{4}$ CAMÕES, 1990, p.185. 
“...Pedro Álvares do que?" por um funcionário irritado e impaciente, como todos os burocratas. Vejamos em que contexto se dá o retorno nas palavras do próprio escritor:

Os que regressavam consigo, clérigos, astrólogos genoveses, comerciantes judeus, aias, contrabandistas de escravos, brancos pobres do Bairro Prenda, do Bairro da Cuca, abraçados a volumes de sepilheira, as malas atadas com cordéis a cestos de verga, brinquedos quebrados, formavam uma serpente de lamentos e miséria aeroporto adiante, empurrando a bagagem com os pés (na faixa reservada aos passageiros em trânsito passavam irlandeses altos e desgrenhados como pássaros de rio) na direção de uma secretária a que se sentava em um escapelo, um escrivão da puridade que lhe perguntou o nome (Pedro Álvares de quê?), o conferiu numa lista dactilografada cheia de emendas e de cruzes a lápis, tirou os óculos de ver ao perto para o examinar melhor, inclinado de banda no poleiro de fórmica, passeou o polegar errático no bigode e inquiriu de repente. Tendes família em Portugal?..."

No sentido que se dá, neste contexto, a Pedro Álvares Cabral, estamos diante de um outro, de um sósia, e não de um dos grandes heróis da navegação portuguesa. Destronado da sua posição de herói, desvestido do poder de quem, inclusive estabeleceu relações comerciais entre Portugal e as Îndias, ele se nos afigura um sósia de si mesmo. Como diria Bakthin, um sósia paródico. Mencionam-se entre os retornados, muito em especial, clérigos, astrólogos genoveses, contrabandistas de escravos, numa alusão clara aos instrumentos mais precisos do poder português, quais sejam, os que detinham o poder ideológico da Igreja, os que dominavam o conhecimento dos oceanos e os que enriqueciam Portugal através do comércio de escravos. Todos eles misturados aos retornados miseráveis e pobres numa atitude completamente paródica diante da história. É como se eles estivessem personificando uma queda, como diria Bakthin, no seu estudo sobre Rabelais, deslocando o que estava em cima para baixo, numa desconstrução completa de antigas hierarquias. Todavia, em Bakthin

${ }^{5}$ ANTUNES, 1988, p.13-14. 
o tempo brinca e ri. É o garoto brincalhão de Heráclito que detém o poder supremo no universo ('à criança pertence a supremacia'). A ênfase é sempre colocada sobre o futuro, cuja face utópica se reencontra constantemente nos ritos e imagens do riso popular que acompanha a festa. ${ }^{6}$

Em Lobo Antunes, o tempo parece ser a "justiça terrível" a que aludem os cristãos, o qual coloca antigos colonizadores, no mesmo lugar e condição dos retornados pobres das antigas colônias africanas. O Pantagruel de Rabelais é o gigante distorcido e disforme que ri feliz da boa forma dos círculos oficiais. Os ridicularizados por Lobo Antunes são a face da decadência. O espelho do grande erro que foi a colonização. O que nos interessa é que há uma coisa em comum entre Lobo Antunes e este riso medieval analisado por Bakthin. Ambos são destronadores, são destruidores da ordem, da hierarquia, são rebaixadores do sublime e dos círculos oficiais. Só que, o que dá a perceber a análise de Bakthin da obra de Rabelais é que, enquanto um dá uma sonora gargalhada ao final de todo esse processo dialético, outro abaixa a cabeça e pensa.

É interessante observar como procedimentos análogos podem levar a resultados tão diferentes. O texto que se segue é um grande exemplo da certeza - postulada por Lobo Antunes - de que a colonização foi este grande erro a que já me referi. Vejamos:

...desde que a telefonia anunciou a independência de Angola decretada por sua Majestade, no rescaldo de um motim, durante as cortes de Lixboa, o odor de suor, da diarréia, do medo, quando colávamos em pânico os armários aos caixilhos porque daqui a nada uma sapatilha esmaga o tapete a rir-se, daqui a nada o MPLA principia a disparar ao acaso e as nucas estoiram como figos numa pasta de carne branca e de grainhas vermelhas, o que julgaria o Infante, se vivo fora, lá na escola de Sagres, desdobrando mapas e consultando estrelas frente às janelas do mar enquanto os seus capitães perseguiam dinamarquesas nas praias de Albufeira e Gil Eanes se apresentava em Lagos, pingando como um noivo exausto, com um ramo de florinhas murchas na mão. ${ }^{7}$

\footnotetext{
${ }^{6}$ ANTUNES, 1988, p.13-14.

${ }^{7}$ ANTUNES, 1988, p.15.
} 
Não há nenhum motivo para riso nesta visão da história, ao contrário. Ninguém de bom senso riria diante da visão de nucas estourando como figos em razão de tiros dados ao acaso. Esta abordagem, entretanto, faz entrever, pela censura imanente, uma idealização da história que tem uma parcela de utopia. A visão do Infante na escola de Sagres trai um certo romantismo que vai se esboroar na ridicularização de Gil Eanes, iniciador das grandes navegações com a descoberta do Cabo Bojador, que, em correlação com o feito, poder-se-ia acreditar un hombre.

Esta transformação de heróis em figuras ridículas aproxima Lobo Antunes do procedimento rabelaisiano. Apresenta-se, não somente a vitória do riso popular, como em Rabelais, mas o medo, a miséria, a dor. É como se o autor nos dissesse que o chicote mudou de dono, mas continua estalando. Nucas estouram ao sabor de tiros ocasionais. Sobre o destino dos grandes navegadores o autor nos diz:

Quase que aposto que morreram todos há séculos, sepultados sob o lajedo das igrejas com o nome em latim apagado por solas de noviças, acomodados no tecido de cor de pérola dos caixões, vestidos de casacos de xadrez, de xailes lilases, de blusas claras, de mão postas e malares agudos como as estátuas jacentes nas criptas das capelas. ${ }^{8}$

Vejamos agora como Camões entra em cena:

Era uma vez um homem de nome Luís

a quem faltava a vista esquerda, que permaneceu no cais de Alcântara

três ou quatro semanas pelo menos, sentado em cima do caixão do pai, à espera que o resto da bagagem aportasse no navio seguinte.

O triunfalismo português necessitava não apenas da mitologia grega mas dos seus próprios construtos. O mito de homens

${ }^{8}$ ANTUNES, 1988, p.15.

9 ANTUNES, 1988, p.19. 
desassombrados, vencedores dos mares tenebrosos pode ter engendrado a lenda segundo a qual Camões teria salvado a nado Os Lusíadas. Talvez esta situação criada por Lobo Antunes, seja um deslocamento do acontecimento pretensamente original. Temos aí duas coisas em comum: o mar e o caixão de um pai, que por analogia corre o risco de um naufrágio, como o poema. O cadáver do pai pode ser o cadáver da épica camoniana com todo o seu elogio triunfal dos feitos portugueses: o deslocamento paródico coloca este passado numa circunstância de negatividade. No caso em questão Camões é muito mais filho do que pai do seu próprio poema. Os Lusíadas fizeram Camões. Os Lusíadas são fruto de um ambiente já armado. Assim sendo este poema é muito mais pai do que filho. O cadáver do pai é o cadáver da épica camoniana, o cadáver do passado. Podemos observar que este mecanismo paródico não leva ao riso, como no riso medieval estudado por Bakthin. Não é uma situação histriônica mas, muito ao contrário, extremamente melancólica.

Todavia, voltando a Camões na narrativa de Lobo Antunes, o trecho a seguir me parece um travestimento paródico da situação pretensamente original, resguardadas as reflexões anteriores. Vejamos:

Dera aos estivadores, a um sargento português bêbedo e aos empregados da alfândega a escritura da casa e o dinheiro que trazia, vira-os içar o frigorífico, o fogão e o chevrolet antigo, de motor delirante para uma nau que aparelhava já, mas recusou-se a separar-se da urna... ${ }^{10}$

Este “...recusou-se a separar-se da urna”, pode muito bem ser um travestimento paródico da recusa de Camões em separar-se do seu poema. Novamente podemos observar um transtorno dos modelos originais no uso que se faz neste contexto da presença das naus. A nau que aí aparece tem, como objetivo, não protagonizar um destino glorioso, mas pura e simplesmente carregar um cadáver.

${ }^{10}$ ANTUNES, 1988, p.19. 
No caso, o cadáver do pai do poeta que, por uma inversão paródica, estamos considerando ser a própria épica camoniana, o próprio Os Lusíadas. Vários personagens ao longo do percurso da obra poderão nos levar ao riso devido ao tratamento que se dá a eles, mas no contexto em que se inscrevem as situações são, no mais das vezes, até sórdidas.

Seguindo a seqüência do percurso narrativo, vamos mostrar agora como se dá a chegada do sósia paródico de Pedro Álvares Cabral, às suas acomodações. A guisa de esclarecimento, ele é acomodado numa pensão miserável que mais tarde funciona como prostíbulo. Neste prostíbulo - chamado Residencial Apóstolo das Índias - a sua mulher vai ser encaminhada à prostituição. O Apóstolo das Índias, Jesuíta espanhol que evangelizou este país e que é venerado como santo em Portugal, aparece, aí, como um decadente dono de prostíbulo, como uma personagem absolutamente escatológico. Este procedimento se encaixa perfeitamente no procedimento rabelaisiano de provocar a queda do sublime ao grotesco para destronar e achincalhar a tirania do discurso oficial. Da condição de santo venerável a dono de prostíbulo, o salto é grande e qualitativo e nos remete à seguinte reflexão: não seria a religiosidade do século XVI uma mercadoria a mais, de grande poder de amansamento ideológico, no sentido do estabelecimento de boas relações comerciais com as colônias? Neste sentido os religiosos figuram como comerciantes da fé que ajudam no processo de realização do comércio. Como prostituidores de almas. Neste sentido, Francisco Xavier, o Apóstolo das Índias, passa por um processo de desmascaramento e é rebaixado à condição de agenciador de prostitutas, visando a desnudar, usando o código da paródia, o discurso oficial. Vejamos como o personagem é apresentado e como Pedro Álvares Cabral o vê:

O Senhor Francisco Xavier, indiano gordo de sandálias, recebeu-o no camarote do vestíbulo cercado de uma dúzia de indianozinhos, todos parecidos com ele, igualmente gordos e de sandálias, de tamanhos diversos como a escala de teclas de um xilofone. Cheirava a insônia e 
a pés, cheirava ao estrume do curral da miséria, e percebia-se o andamento de migrações das nuvens pelos orifícios do reboco como se houvesse, também guerra aqui, pensou Pedro Álvares Cabral, como se um morteiro diminuísse os prédios". ${ }^{11}$

Estamos diante de uma imagem grotesca.

Na cultura popular da idade média, o grotesco, como é o caso da figura em questão, pode ser usado para aproximar o mundo do homem, para reintegrá-lo por meio do corpo, à vida, mas pode também usar o recurso dos espantalhos cômicos, ou seja, apresentar a questão "na forma do terrível vencido pelo riso". ${ }^{12}$

Este sósia paródico do santo espanhol, venerado em Portugal, pode bem nos levar à reflexões sobre a diferença entre a paródia moderna e a paródia medieval. Este personagem assim apresentado na obra de Lobo Antunes, vem como um emblema de decadência, prostituição e miséria moral, coisa que demonstrarei nas várias faces dele.

Vimos alguns aspectos da épica camoniana. Sobretudo o triunfalismo ufanista que envolveu deus e deuses na construção do imperialismo que definiu a história portuguesa no século XVI. Comparando Os Lusíadas com Lobo Antunes, a sensação que se tem é a de uma queda. Neste sentido, a obra de Lobo Antunes é o dedo em riste que joga os anjos no chão, mas, diferentemente do contexto medieval não ri desta queda. Apenas provoca. O próprio Bakthin faz reflexões bem parecidas com a que eu estou fazendo sobre as diferenças entre a paródia medieval e a paródia moderna. A diferença é que, a meu ver, o que a experiência moderna perde não é a naturalidade, como diz Bakthin, mas é um pouco da comicidade. O homem moderno se pretende sério, antena da raça como diria Ezra Pound.

Neste sentido, a obra de Lobo Antunes me parece uma paródia amarga da história de Portugal! Talvez seja interessante comparar tudo

11 ANTUNES, 1988, p.32.

12 BAKTHIN, 1993, p.34. 
o que foi dito até agora sobre o riso medieval, com as palavras de Linda Hutcheon sobre romancistas contemporâneos; ela diz: "Romancistas e poetas como Leonard Cohen tornam-se deliberadamente cantores pop numa tentativa de chegar ao povo mas, mesmo assim, o pessimismo irônico vem substituir o utopismo otimista de Bakthin". ${ }^{13}$ Este é o percurso da paródia em Lobo Antunes. Apesar de ser uma transgressão do discurso oficial, não leva ao riso pura e simplesmente, mas à reflexão.

Vejamos mais alguns passos da obra em direção à tipificação do sósia paródico de Francisco Xavier. À guisa de esclarecimento, este sósia, num dos passos do percurso da obra, exige que Pedro Álvares Cabral coloque a própria mulher trabalhando como prostituta, para pagar a sua estadia no prostíbulo. Isto aconteceu nos seguintes termos: - "A tua esposa vai trabalhar lá embaixo num bar até a contazinha da pensão ficar paga, decidiu o indiano a esfregar com empenho a fazenda das virilhas". ${ }^{14}$

O que no estudo de Bakthin aparece como uma reflexão sobre o baixo material corporal como configurador da degradação paródica que visava a achincalhar os círculos oficiais, está aqui claramente expresso. O santo coçando a virilha numa experiência meio sórdida de fatuidade sexual. Mas enquanto em Lobo Antunes, este ato é ícone de decadência moral, em Rabelais é recondução à condição humana. Em Rabelais, Pantagruel coçaria as virilhas para escandalizar alguma dama da nobreza.

Para fechamento da reflexão sobre o processo paródico no que diz respeito ao sósia de Francisco Xavier, o autor nos reúne três personagens emblemáticos da respeitabilidade heróica na história portuguesa, a saber: o mesmo Francisco Xavier, cujas coordenadas já foram explicitadas, Manoel de Sousa Sepúlveda, morto num naufrágio no Galego São João, e Fernão Mendes Pinto, companheiro

${ }^{13}$ HUTCHEON, 1985, p.95.

${ }^{14}$ ANTUNES, 1988, p.39. 
de Francisco Xavier nas andanças pelos mares do Oriente. Para que se configure de maneira clara a natureza do achincalhe, talvez seja interessante transcrever o prólogo da História Trágico - Marítima sobre Manoel de Sousa Sepúlveda:

Como é esta que se conta neste naufrágio para os homens muito temerem os castigos do senhor e serem bons cristãos, trazendo o temor de Deus diante dos olhos, para não quebrar seus Mandamentos. Porque Manoel de Sousa era um fidalgo mui nobre e bom cavaleiro, e na Índia gastou em seu tempo mais de cinqüenta mil cruzados em dar de comer a muita gente, em boas obras que fez a muitos homens... ${ }^{15}$

A transcrição desta passagem tem como objetivo demonstrar o percurso que se faz do texto oficial, sério, ao texto paródico. Vejamos como estes três personagens aparecem reunidos na obra analisada: Manoel de Sousa Sepúlveda, entre outras coisas, "entendeu-se com Fernão Mendes Pinto e o senhor Francisco Xavier sobre os pormenores de recrutamento e manutenção de um contingente razoável de mulatas..." ${ }^{\text {16 }}$ Entenda-se, todos os tão nobres personagens, reunidos aqui na condição de agenciadores de prostitutas. $\mathrm{O}$ achincalhe, em si, qualquer um pode fazer. Mas atingir a um fidalgo e a um santo de uma vez só, é, pelo menos desfibrar seriamente a dignidade de representantes expressivos dos círculos do poder. Ou seja, abaixo tudo o que é delicado e hierárquico. Mesmo amargo faz rir. Diferentemente, aqui, o baixo material corporal, tal como é sinalizado em Bakthin, é a expressão de um mundo marcado pelo cinismo e pela dor. Enquanto Pantagruel faz xixi na nobreza e ri, Pedro Álvares Cabral urina com dor:

Se acordava para urinar, segurando a mãos ambas o odre da bexiga, o bicho obrigava-o a expulsar pela uretra ciscos tão aguçados como pingos clorídricos, que abriam caminho, através da sua carne, numa

${ }^{15}$ BRITO, 1998, p.5.

${ }^{16}$ ANTUNES, 1988, p.126. 
violência abominável que ecoava por muitas horas nas tripas, até que, não agüentando o sofrimento, ofereceu a cabeça, sem qualquer explicação, ao Padre Antônio Vieira... ${ }^{17}$

Ou seja, enquanto na perspectiva de Bakthin, Rabelais usa o apelo ao baixo material corporal para aliviar, para descer à terra, à condição humana e reconduzir à vida, em Antunes, o mundo parece ser um grande hospital, um grande hospício, e o personagem se vê aí obrigado à entregar a cabeça ao discurso oficial, que funciona como um torturante inspector do controle esfincteriano.

Em síntese, a paródia em Lobo Antunes funciona como método, da mesma forma que a paródia rabelaisiana analisada por Bakthin, mas chega a resultados diferentes.

Para finalizar, vou transcrever aqui o que me parece o ápice da parodização dos personagens da história de Portugal. Trata-se do encontro de Vasco da Gama com o rei, depois de uma longa peregrinação de ambos pelas ruas do país, peregrinação esta marcada por situações insólitas e absurdas. Vejamos:

As pálpebras de galo idoso de sua majestade encontraram as minhas, por igual pregueadas e pisadas, e, por momentos assaltou-me a idéia absurda de sermos um único indivíduo que se observava ao espelho, surpreso dos adereços das golas, dos brincos e das fivelas de oiro, de cócoras rente à água salvo de cortesãos e de aduladores mais vulnerável e frágil do que num grumete em desgraça. ${ }^{18}$

Vasco da Gama, cantado e recantado em Os Lusíadas por seu bom senso, malícia e coragem nos é apresentado participando de um encontro que tem algo de patético. Vejamos como D. Manoel é apresentado - "mais vulnerável e frágil do que um grumete em desgraça". Novamente o mesmo procedimento descrito por Bakthin, com relação à obra de Rabelais. O forte, relegado a posição de frágil, o alto deslocado dos cumes da glória à baixa posição da fragilidade.

17 ANTUNES, 1988, p.127-128.

${ }^{18}$ ANTUNES, 1988, p.121. 
Apesar dos resultados serem diferentes, o procedimento é o mesmo. Ainda Vasco da Gama reflete:

Queria dizer-lhe, à medida que as tágides se evaporavam, uma após outra, no betume das ondas, do meu regresso à Lixboa num porão de lençóis ensopados de vômito e de enervada miséria". ${ }^{19}$

A evaporação das tágides, substituídas por vômitos e diarréias, novamente uma queda do sublime ao grotesco, do sonho camoniano ao chão, é outra vez um recurso rabelaisiano. Mas enquanto Rabelais ri, Lobo Antunes pensa. Vejamos mais um passo desse reencontro:

Vasco da Gama e o monarca decidiram-se por um talude junto ao rio, D. Manoel despido da coroa de lata e do manto de arminho e o marinheiro desembaraçado do peso da espada, e sentiram-se finalmente iguais, na sua decrepitude e no seu cansaço, ao cabo de tantas separações, equívocos, amuos e intrigas de escudeiros". ${ }^{20}$

Descoroamento e desarmamento, procedimentos essencialmente rabelaisianos e paródicos.

Em Bakthin, a compreensão da paródia na obra de Rabelais resgata e confere poder ao riso popular. Trata-se de uma alegria que todos nós temos contemporaneamente que é a de ridicularizar ditadores e tiranos, ridicularizar atitudes pernósticas e pouco naturais em relação à vida, que é a de alargar os espartilhos e deixar sobressair o ventre como forma de demonstrar a glória da abundância e da alegria de viver.

Segundo observações e reflexão de Linda Hutcheon, a paródia medieval ocupava o espaço autorizado do carnaval, das festas populares.

A mim, me parece que o espaço de uma romance, assim como a paródia medieval, é muito pouco para desafiar convicções antigas e um discurso de séculos.

\footnotetext{
19 ANTUNES, 1988, p.121.

${ }^{20}$ ANTUNES, 1988, p.120.
} 
Segundo Linda Hutcheon

este paradoxo da subversão legalizada, embora não oficial, é característica de todo o discurso paródico na medida em que a paródia postula, como pré-requisito para a sua própria existência, uma certa institucionalização estética que acarreta a aceitação de formas e convenções estáveis e reconhecíveis. ${ }^{21}$

Talvez seja interessante lembrar a posição de Jameson a respeito da possibilidade, não do discurso dialógico, mas, sobre o lugar do dislógico. Do discurso antagônico. Talvez a alegria popular, ocupando o espaço do lugar autorizado não seja suficiente para as mudanças. A amargura de Lobo Antunes talvez tenha mais sentido. Mesmo que não tenhamos tido o poder real de destronar reis ou de sobreviver aos ditadores, quem sabe possamos sobreviver pelo menos a nós mesmos sem a falsa ilusão do poder do riso. Neste sentido, As Naus funciona a meu ver como este direito à dislogia, a responder a um Logos com outra coisa, com um absurdo talvez, com um sonoro "não falamos a mesma linguagem". Talvez esta seja uma forma bem original de alteridade. Apesar de engraçados, os sósias paródicos de Lobo Antunes não nos autorizam a gargalhada sonora de vencedores, nós, estudantes, professores, intelectuais, mal pagos e insones. Porque existe uma parcela de piedade por estes sósias no texto, muito subreptícia, mas existe. Um rei destronado de uma coroa de lata, com sinais de diabetes, inspira piedade. Marinheiros em busca de ninfas do Olimpo inspiram piedade. E até proxenetas miseráveis, são pobres diabos que inspiram piedade.

Daí a ausência do sentido do riso em toda a obra. A construção desses sósias leva muito mais a esse sentimento do que ao riso. É como se o escritor fosse um viajante de uma nau sem rumo e aportasse no bestiário da história.

Assim sendo,

${ }^{21}$ HUTCHEON, 1984, p.96. 
cada vez mais Lixboa se lhe afigurava um rodopio de casas sem destino, uma cavalgada de algerozes, de tapumes, de flechas, de igrejas e de ruas a quem as obras camarárias expunham as tripas dos esgotos sob um céu rebentado de pústulas de nuvens. ${ }^{22}$

Só fala com esse desalento quem sonha.

Só desdenha o passado quem esperou muito dele.

\section{Bibliografia}

ANTUNES, Antônio Lobo. As Naus. Lisboa: Publicações Dom Quixote Ltda. Círculo de Leitores Ltda, 1988.

BAKTHIN, Mikail. A cultura popular na Idade Média e no Renascimento, O Contexto de François Rabelais. São Paulo: Ed. Hucitec, 1993.

CAMÕES, Luís de. Os Lusíadas. Belo Horizonte: Ed. Itatiaia, 1990.

GOMES DE BRITO, Bernardo. História Trágica Marítima. Rio de Janeiro: Editora Nova Aguilar, 1998.

HUTCHEON, Linda. Uma teoria da paródia. Lisboa. Rio de Janeiro: Edições 70, 1985.

MAGALHÃES, Álvaro. Dicionário Enciclopédia Brasileiro. Rio de Janeiro, Porto Alegre, São Paulo: Editora Globo, 1957.

SARAIVA, Antônio José. Para a bistória da cultura em Portugal. Portugal: Publicações Europa América, 1972.

${ }^{22}$ ANTUNES, 1988, p.237. 


\section{Resumo}

Tomando por base a obra As Naus, de Antônio Lobo Antunes, procedi a uma análise do exercício da paródia levado a efeito pelo autor. Comparando o procedimento parodístico neste escritor com o riso medieval observei que, tanto no caso em questão como no riso medieval, estudado por Mikail Bakthin no seu estudo sobre Rabelais, observa-se uma queda do sublime ao grotesco, no sentido de achincalhar os círculos oficiais. Todavia, enquanto em Rabelais esse rebaixamento visa à uma recondução à condição humana, em Lobo Antunes nos apresenta toda uma galeria de personagens notáveis da história de Portugal completamente desvestidos da sua aura de heroismo e reconduzidos à banalidade e ao non-sense do mundo contemporâneo. A escolha do título deste estudo se dá em razão de se observar que o tratamento que é dado aos personagens os transforma em sósias paródicos dos atores da história de Portugal.

\section{Resumen}

Tomando como base la obra As Naus (Los Navios), de Antônio Lobo Antunes, procedí a un análisis del ejercicio de la parodia llevado a cabo por al autor. Comparando el procedimento parodístico de este escritor con el humorismo medieval observe que, tanto en el caso parodístico como en al humorismo medieval, estudiado por Mikail Bakthin en su estudio sobre Rabelais, se observa una tendencia de lo sublime a lo grotesco, en el sentido de ridicularizar los círculos oficiales. A pesar que en Rabelais esse rebajamiento apunta a una reconducción de la condición humana, Lobo Antunes nos presenta toda uma exposición de personajes notables de la historia de Portugal completamente desnudos de su aura de heroismo y devueltos a la trivialidad y al non-sense del mundo contemporaneo. Escojí el título de este estudio en razón de observarse que el tratamiento dado a los personajes los transforma en sosias parodicos de los actores de la historia de Portugal. 